\title{
Effect of Helicobacter pylori infection on chronic periodontitis by the change of microecology and inflammation
}

\author{
Zhekai Hu$^{1}$, Yu Zhang ${ }^{1}$, Zhiyu Li ${ }^{2}$, Yuedi Yu ${ }^{3,4}$, Wenyan Kang ${ }^{1,5}$, Yingnan Han², Xiwen \\ Geng', Shaohua Ge ${ }^{1,5}$, Yundong Sun ${ }^{2}$ \\ ${ }^{1}$ Shandong Provincial Key Laboratory of Oral Tissue Regeneration, School of Stomatology, Shandong University, Jinan, \\ Shandong 250012, People's Republic of China \\ ${ }^{2}$ Department of Microbiology, Key Laboratory for Experimental Teratology of Chinese Ministry of Education, School of \\ Medicine, Shandong University, Jinan, Shandong 250012, People's Republic of China \\ ${ }^{3}$ Shanghai Southwest Weiyu Middle School, Shanghai 200233, People's Republic of China \\ ${ }^{4}$ Laboratory of Oral Tumor Biology, Shanghai Research Institute of Stomatology Ninth People Hospital, Shanghai Jiao Tong \\ University School of Medicine, Shanghai 200011, People's Republic of China \\ ${ }^{5}$ Department of Periodontology, School of Stomatology, Shandong University, Jinan, Shandong 250012, People's Republic \\ of China
}

Correspondence to: Shaohua Ge, email: shaohuage@sdu.edu.cn Yundong Sun, email: syd@sdu.edu.cn

Keywords: Helicobacter pylori, Wnt5a, IL-8, chronic periodontitis, inflammation

Received: April 30, 2016 Accepted: August 11, $2016 \quad$ Published: August 20, 2016

\section{ABSTRACT}

Helicobacter pylori (H. pylori), a pathogen inducing peptic disease, is recently found to be binding to the progress of periodontitis. Most previous studies are case-controlled, and they investigate the risk of $H$. pylori infection in disease the development of while few studies evaluate the correlation between $H$. pylori and periodontal pathogens. Therefore, we investigated the correlation between $\boldsymbol{H}$. pylori infection with periodontal parameters, periodontal pathogens and inflammation. The results indicated that patients with $H$. pylori showed significantly higher probing depth and attachment loss than those without $(p<0.05)$. Among 28 subgingival plaque samples from 14 patients, the frequencies of Porphyromonas gingivalis, Prevotella intermedia, Fusobacterium nucleatum and Treponema denticola were significantly higher with $H$. pylori infection than those without $H$. pylori infection $(p<0.05)$. However, the frequency of Aggregatibacter actinomycetemcomitans was lower $(p<0.05)$. Furthermore, after human acute monocytic leukemia cell line (THP-1) was stimulated with cagA-positive standard strains (cagA ${ }^{+}$H. pylori 26695), the expression of periodontitis-related molecules Wnt5a, interleukin 8 (IL-8), interleukin 6 (IL-6) and interferon gamma (IFN-y) significantly increased $(p<0.05)$. Conversely, the expression of tumor necrosis factor alpha (TNF-a) was almost stable. Meanwhile, $\mathrm{cagA}^{+} \mathrm{H}$. pylori promoted significantly higher expression of IL-8 and Wnt5a than isogenic cagA mutants strains (cagA- H. pylori 26695) did. Taken together, our data suggested that $H$. pylori might promote the growth of some periodontal pathogens and aggravate the progress of chronic periodontitis.

\section{INTRODUCTION}

Periodontitis is one of the most prevalent diseases, and it influences up to $90 \%$ people in the world [1]. Varying from other infectious diseases, periodontitis is a multiple bacteria-related disease. As the most important etiology, periodontal pathogens have been studied for decades. In 1996, 11 periodontitisrelated pathogens had been determined including three strong associated pathogens and eight moderate associated pathogens including Aggregatibacter actinomycetemcomitans, Porphyromonas gingivalis, Bcteroides forsythus, Prevotella intermedia, Prevotella nigrescens, etc [2]. 
Multiple experimental methods have been used in detecting periodontal pathogens. However, more than 50\% of bacteria cannot be cultivated. In recent years, techniques such as PCR, sequencing and DNA hybridization have been used to identify bacterial species in samples such as plaque and soil [3], and about 1,000 bacterial species have been found in human oral cavity [4], which led to a development in the area of periodontitis as well. Previous studies found that periodontal diseases occurred due to the change of periodontitis-related bacterial species in subgingival plaque [5]. Meanwhile, the correlation between oral diseases and systematic diseases such as rheumatic heart disease, glomerulonephritis and gastric disease has been reported these years [6-8]. Among these, the effect of Helicobacter pylori (H. pylori) on periodontitis became a new hotspot.

$H$. pylori is a typical Gram-negative organism which needs to grow under a microaerophilic environment. It is generally studied for its peptic disease-induced function [9]. With the development of the detection methods, H. pylori has been found to have a close connection with many diseases such as chronic liver disease, oral lichen planus and periodontitis [10]. Desai et al. first found the bacteria in human plaque [11]. Since then, the connection between $H$. pylori and periodontal diseases had been studied. Previous reports have found that people with H.pylori infection tend to have periodontitis.

Meanwhile, considerable research articles including clinical and experimental studies have reported the relationship between $H$. pylori infection and periodontitis [12-14]. However, some studies showed that there was no correlation between $H$. pylori infection and periodontal status [15]. Moreover, most the related studies focus on clinical index, few investigated the correlation between microorganisms and the molecular expression of inflammatory proteins. Those seemed to be apparent defects in this research area. What we have done was to detect the correlation among those by the methods of molecular biotechnology. The results did show us some interesting phenomenon.

Moreover, latest study reported the Wingless proteins (Wnt) family and the expression of cytokines were correlated to the process of chronic periodontitis [16]. Wnt is one of the most important proteins involved in the development of embryo and the differentiation of blood cells and lymphocytes [17]. Among those, Wnt5a came into our view. Wnt5a could be secreted by inflammatory tissues, antigen-presenting cells and rheumatoid arthritis joints [18] and promote tumor proliferation and stromal vascular endothelial growth factor [19]. In primary human gingival fibroblasts (HGF), the expression of Wnt5a mRNA was rather constant after stimulation with $P$. gingivalis LPS. On the contrary, in primary monocytes, the expression of Wnt5a mRNA significantly increased by $P$. gingivalis LPS and reduced by using NF-kB inhibitor MG132. These results suggest that monocytes, but not HGF, play an important role in Wnt5a up-regulation at inflamed site. In this study, Wnt5a served as an important molecule to detect the status of inflammation.

Cytokines could induce inflammation and act as important molecules in angiogenesis [20], the progress of human chronic periodontal inflammation and the development of some cancer [21-23]. Cytokines such as interleukin 6 (IL-6), interleukin 8 (IL-8), tumor necrosis factor alpha (TNF- $\alpha$ ) and interferon gamma (IFN- $\gamma$ ) could be produced by immunocytes in inflammatory tissues. Numerous studies examining protein expression in patients with periodontitis also showed that periodontitis would increase the secretion of those cytokines [24, 25]. Cytokine played an important role in the progression of chronic periodontitis as well [26]. Meanwhile, many reports found that $H$. pylori infection associated with a cagA-positive phenotype could stimulate the immune system and gastric epithelial cell lines, which would lead to the release of cytokines [27]. Reti KL found dysbacteriosis could also happen by the change of IL- 8 concentration [28]. All of those suggested that cytokines were important in the progress of $H$. pylori infection.

Hence, in this study, we aimed to determine the association of $H$. pylori infection with periodontal disease, and the difference in microorganism environment with and without the infection and the effect of $H$. pylori on immune cells.

\section{RESULTS}

\section{Detection of $H$. pylori infection by real-time PCR}

28 samples from 14 patients with chronic periodontitis were involved in our study, and real-time PCR was performed to determine if they were infected with $H$. pylori. All basic clinical features of two groups were shown in Table 1 and Table 2. By statistical analysis, no significant difference in basic periodontal clinical characteristics which suggested the experiment grouping design was appropriate (Table 1). The result indicated that patients with and without H. pylori infection did not differ in plaque index (PLI) and bleeding index (BI) $(p>0.05)$ (Table 2), while patients with H. pylori exhibited deeper probing depth (PD) and more attachment loss (AL) than those without $(p<0.05)$ (Table 2$)$.

\section{Bacteria in plaque samples}

The frequencies of different bacteria in subgingival plaque samples from patients with or without $H$. pylori infection (Figure 1) were determined. By two-way $t$-test, the frequencies of $S$. mutans and $S$. sanguis showed no significant relation with the infection of $H$. pylori. However, those of $P$. gingivalis, $P$. intermedia, $F$. nuclearum and $T$. denticola were significantly higher in samples with $H$. pylori infection than those without $(p<0.05)$. Conversely, the frequency of A.actinomycetemcomitans was lower in H. pylori infection samples $(p<0.05)$. Therefore, not all 
Table 1: Basic periodontal clinical characteristics of patients with and without Helicobacter pylori infection

\begin{tabular}{lcc}
\hline \multicolumn{1}{c}{ Characteristics } & H. pylori positive & H. pylori negative \\
\hline Age (years; mean $\pm \mathrm{SD})$ & $35.15 \pm 2.891$ & $38.00 \pm 2.580$ \\
Males & $9(13)$ & $8(15)$ \\
Smokers & 0 & 0 \\
Antibiotic usage & 0 & 0 \\
Systemic diseases & & \\
Cardiovascular disease & 0 & 0 \\
Diabetes & 0 & 0 \\
Arthritis & 0 & 0 \\
Thyroid & 0 & 0 \\
Asthma & 0 & 0 \\
Depression & 0 & 0 \\
\hline
\end{tabular}

No difference between groups by $t$ test.

Table 2: Periodontal indexes of patients with and without $H$. pylori infection

\begin{tabular}{lccc}
\hline \multicolumn{1}{c}{ Periodontal indexes } & H. pylori positive & H. pylori negative & p value \\
\hline Plaque index & $2.231 \pm 0.1216$ & $2.067 \pm 0.0667$ & $p>0.05$ \\
Bleeding index & $2.462 \pm 0.2683$ & $2.333 \pm 0.1869$ & $p>0.05$ \\
Probing depth (mm) & $5.846 \pm 0.4507^{*}$ & $4.667 \pm 0.1869$ & $p<0.05$ \\
Attachment loss (mm) & $7.231 \pm 0.3782^{*}$ & $6.133 \pm 0.2153$ & $p<0.05$ \\
\hline
\end{tabular}

Data were expressed as mean $\pm \mathrm{SD}$. Periodontal index of each site from selected patients were measured.

*There was significant difference between patients with and without $H$. pylori in probing depth and attachment loss.

bacteria in subgingival plaque had a close relationship with H. pylori. And the total ratio of periodontal pathogens in H. pylori-positive samples was more than that in H. pylorinegative samples (Figure 2).

\section{The expression of Wnt5a increased in THP-1 cells with $\mathrm{cag} A^{+} \mathrm{H}$. pylori and $\mathrm{cag} A^{-} \mathrm{H}$. pylori stimulation}

THP-1 cells were infected with $\operatorname{cag} A^{+} H$. pylori for different time points $(0,0.5,1,2,4$ and $8 \mathrm{hrs})$ and at different ratios $(0,20: 1,50: 1,100: 1,150: 1$ and 200:1). Then, mRNA and total protein were obtained to detect the expression of Wnt5a in mRNA and protein level. Our results illustrated that the expressions of Wnt5a mRNA in THP-1 cells stimulated with $H$. pylori were stable at $0,0.5,1,2$ and $4 \mathrm{hrs}$ $(p>0.05)$ while increased dramatically at $8 \mathrm{hrs}(p<0.05)$ (Figure 3A). Moreover, H. pylori enhanced Wnt5a mRNA expression at a dose-dependent manner, with the maximum effect appeared at the ratio of 200:1 $(p<0.05)$ (Figure 3B).

Then, THP-1 cells were infected by $\operatorname{cag} A^{+} H$. pylori and cag $A^{-} H$. pylori at increasing ratio of $H$. pylori (at the ratios of 100:1 and 200:1) for $8 \mathrm{hrs}$. Wnt5a expression increased in both groups. However, more dramatic expression happened in the group of $\mathrm{cagA}^{+} \mathrm{H}$. pylori (Figure 3C).

\section{The expression of IL-8 increased in THP-1 cells with stimulation of $\mathrm{H}$. pylori}

RT-PCR and ELISA were used to evaluate the expression of IL-8. The expression and secretion of IL-8 showed time- and dose-dependent manners (Figure 4).

Interestingly, in the protein secretion level, there were no differences among $0 \mathrm{hr}, 0.5 \mathrm{hr}$ or $1 \mathrm{hr}$. And significant differences happened from $2 \mathrm{hrs}$ to $8 \mathrm{hrs}$, and similarly peaked at $8 \mathrm{hrs}(p<0.05)$ (Figure 4C).

In dose-control groups, the expression of IL-8 gradually increased in mRNA level, and peaked at the ratio of 150:1 while stable increase could be found in protein secretion level $(p<0.05)$ (Figure 4B, Figure 4D).

After stimulated by $\mathrm{cag} A^{-} H$. pylori, the expression of IL-8 increased slowly, but was still far down from the stimulation by $\operatorname{cag} A^{+} H$. pylori in both dose and time control groups (Figure 4E, Figure 4F).

\section{The secretions of IL-6 and IFN- $\gamma$ increased but that of TNF- $\alpha$ was stable in THP-1 cells with stimulation of $\boldsymbol{H}$. pylori}

ELISA was used to evaluate the expression of IL-6, IFN- $\gamma$ and TNF- $\alpha$. The secretion of these three cytokines showed different manners from IL- 8 and the secretion 
quantities of those were much lower than that of IL-8 (Figure 5).

Firstly, IL-6 showed time- and dose-dependent manners in protein levels (Figure 5A, Figure 5B). Likewise, the secretion of IFN- $\gamma$ was increased from $0 \mathrm{hr}$ to $4 \mathrm{hrs}$, but declined afterwards. While in dose control group, the highest expression occurred in the ratio of 50:1 but fell down since then.

Conversely, the secretion of TNF- $\alpha$ was relatively stable after stimulation with $H$. pylori. Rare dramatic changes could be found in both dose and time control groups.

\section{DISCUSSION}

In this study, clinical features were analyzed and deeper PD and AL were found in sites with $H$. pylori infection. Then in plaque samples, we found the frequencies of $S$. mutans and $S$. sanguis showed no correlation with the infection of $H$. pylori. However,
A

Porphyromonas gingicalis (P.g)

\begin{tabular}{|c|c|}
\hline & 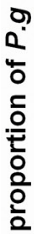 \\
\hline
\end{tabular}
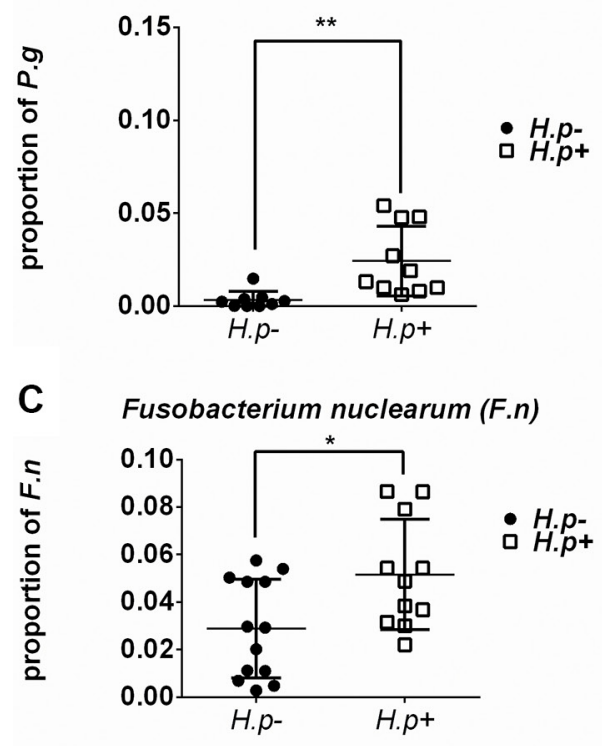

E Actinobacillus actinomycetemcomitans (A.a)
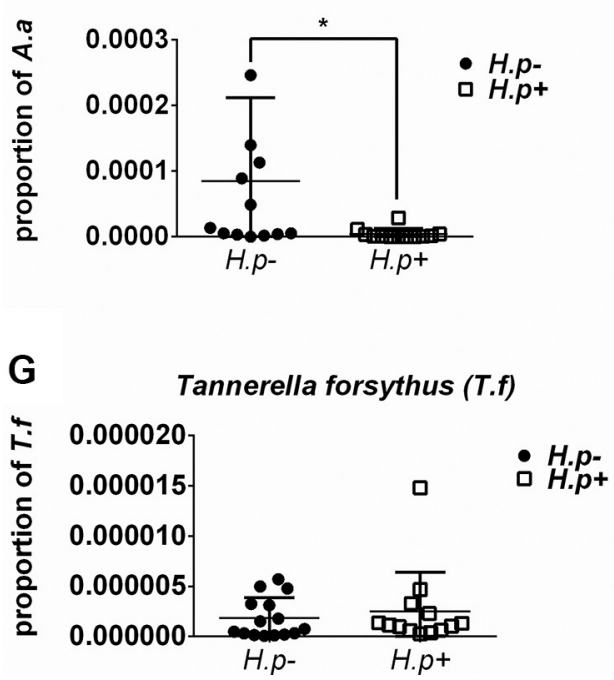

B
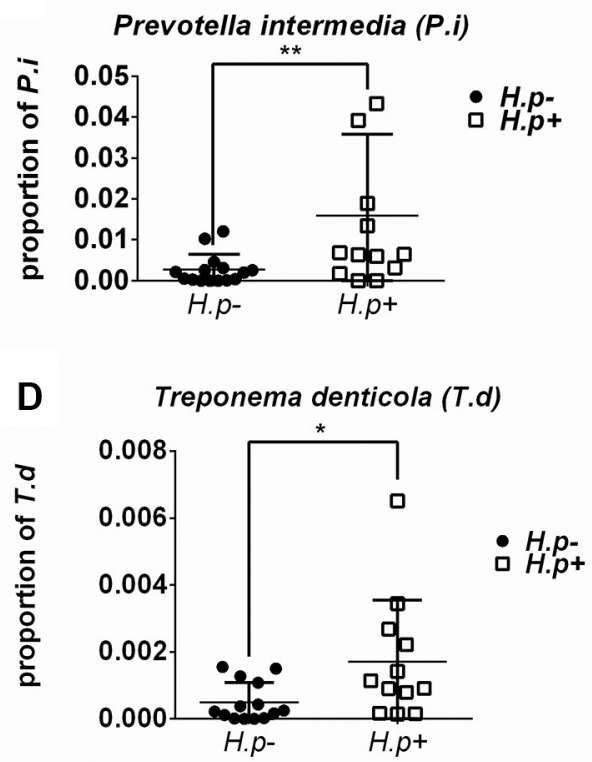

$\mathbf{F}$
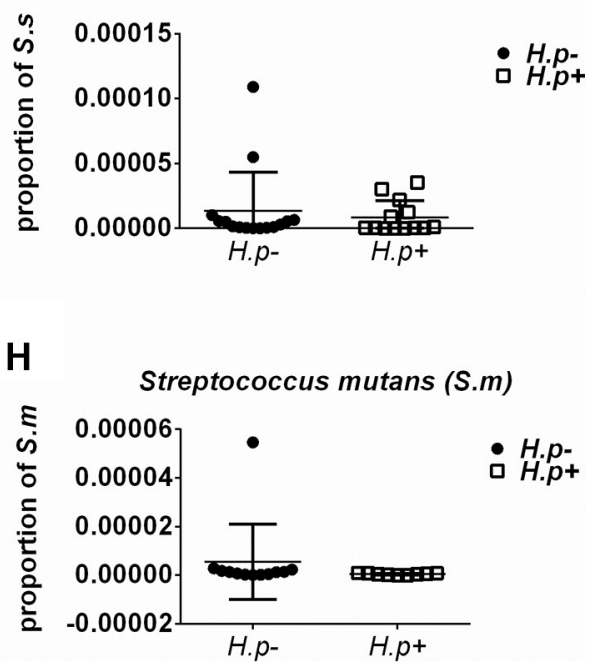

Figure 1: Frequency of bacteria in $\boldsymbol{H}$. pylori-positive and -negative subgingival plaque samples. Real-time PCR detection of target bacteria including Porphyromonas gingivalis (A), Prevotella intermedia (B), Fusobacterium nuclearum (C), Treponema denticola (D), Aggregatibacter actinomycetemcomitans (E), Streptococcus sanguis (F), Tannerella forsythus $(\mathbf{G})$ and Streptococcus mutans $(\mathbf{H})$. The proportion of target bacterium was calculated by comparing the circulation threshold of target bacterium to that of the universal primer. $* p<0.05 ; * p<0.01$ by $t$-test. 
those of $P$. gingivalis, $P$. intermedia, $F$. nuclearum and $T$. denticola were significantly higher in samples with H. pylori infection than those without.Conversely, the frequency of A.actinomycetemcomitans was lower in $H$. pylori infection samples. Meanwhile, periodontitis related protein Wnt5a and cytokines were significantly higher after stimulated with $H$. pylori.

Periodontitis is a widespread plaque-induced disease. In recent years, clinical studies found $H$. pylori in oral cavity, and considerable studies found that the severer the periodontitis was, the higher positive rate of H. pylori could be found [12, 29, 30]. An epidemiological study performed in the USA also reported the relationship between periodontal disease and $H$. pylori infection [13]. Although there were a few studies reported negative findings [15], most related findings were consistent with our findings. In this study, samples were collected from patients with chronic periodontitis and deeper PD and AL were found in $H$. pylori-positive sites. We supposed that $H$. pylori could aggravate periodontal destruction in patients with periodontitis. Therefore, we would like to study the concrete mechanisms under this phenomena.

A wide range of bacteria related to periodontitis was found with PCR technique. With increasing frequencies of some Gram-negative and anaerobic bacteria in biofilms, the inflammation of periodontium could deteriorate $[31,32]$ and cytokines secretion may increase. P. gingivalis, T. forsythia, T. denticola, A. actinomycetemcomitans, even some herpes viruses [33], HIV and some fungi $[1,34]$ were detected from infected periodontal tissues. Here, we determined the frequencies of 5 periodontal pathogens and 2 caries related pathogens in dental plaques with and without $H$. pylori infection by real-time PCR. We found that the frequencies of $P$. gingivalis, $P$. intermedia, $F$. nuclearum and $T$. denticola were higher in samples with $H$. pylori infection than that without, with the exception of A.actinomycetemcomitans. And the total ratio of periodontal pathogens was relatively higher in $H$. pylori-positive samples than those in $H$. pylori-negative samples, which suggested that $H$. pylori might aggregate chronic periodontitis by change of the subgingival microbiota.

Moreover, the relationship of $H$. pylori infection and caries-associated pathogens was also investigated. In a previous study, no correlation was found between the presence of caries-associated pathogens and $H$. pylori infection [35]. Similarly, we found that no significant correlation between caries-related bacteria and $H$. pylori infection, which suggests that H. pylori may be not a kind of caries-related microorganism in human subgingival microecology. Aggressive periodontitis is a relative rare disease and has different disease-related pathogens from chronic periodontitis. A. actinomycetemcomitans was found to be one of the most frequent pathogens identified in patients with localized aggressive periodontitis $[36,37]$. In contrast, we found that the frequency of $A$. actinomycetemcomitans was lower in $H$. pylori-positive samples. Those phenomenon are very interesting, and the mechanism underneath needs further study to address.

Additionally, the level of Wnt5a mRNA expression was also investigated. It had been known that Wnt5a could be expressed by some immune cells including almost all

Total Mean Ratio of Periodontal Pathogens

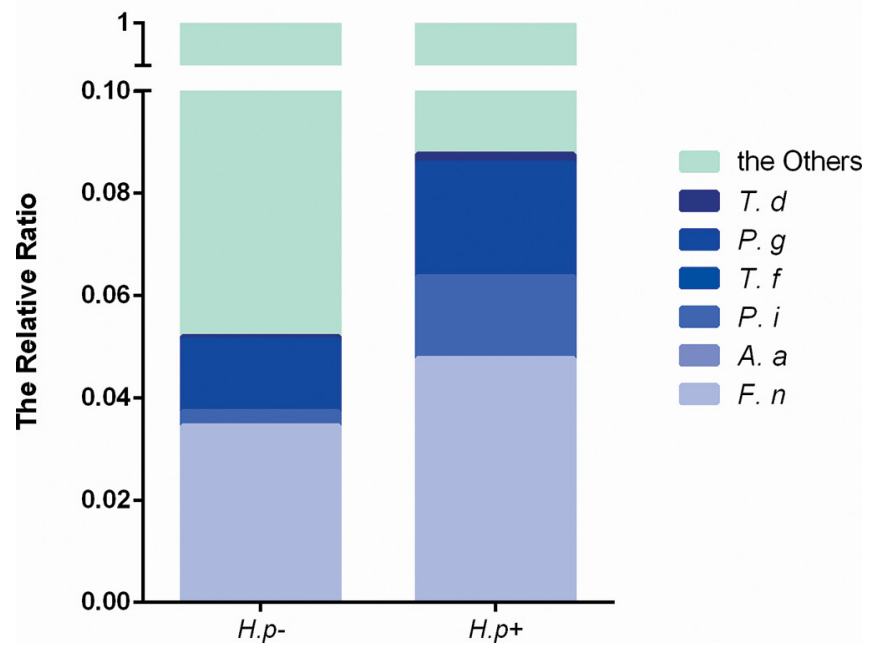

Figure 2: Total ratio of periodontal pathogens in $\boldsymbol{H}$. pylori-positive and -negative subgingival plaque samples. Real-time PCR detection of periodontal pathogens including Porphyromonas gingivalis, Prevotella intermedia, Fusobacterium nuclearum , Treponema denticola, Aggregatibacter actinomycetemcomitans and Tannerella forsythus. The proportion of target bacteria was calculated by comparing the circulation threshold of target bacteria to that of the universal primer. The total ratio of periodontal pathogens was added by calculating the mean of each bacterium. 
antigen-presenting cells [38] and it has been considered as one of the key molecular in chronic periodontitis recently. In a previous study, HGF-1 cells constantly expressed Wnt5a mRNA with the stimulation of $P$. gingivalis, while the expression of Wnt5a mRNA in THP-1 cells showed a dose-dependent manner. Therefore, Wnt5a might be a periodontitis-related protein and could suggest the potential periodontal destruction [16]. In this study, THP-1 cells stimulated with $H$. pylori showed a doseand time-increased expression and secretion of Wnt5a. Interestingly, cag $A^{+} H$. pylori significantly up-regulated the expression of Wnt5a. The result suggested that in response to periodontitis, the genes of Wnt superfamily may be activated by $H$. pylori and $H$. pylori may enhance the expression of Wnt5a and induce the development of periodontitis. Meanwhile, CagA might play an essential role in this process.
Furthermore, the dose- and time-dependent of IL-8 on expression were first studied. According to the result, the expressions of IL-8 increased significantly after the stimulation of $H$. pylori. The overall effect of the stimulation of $H$. pylori was consistent with previous findings [39]. The production of different cytokines could be induced by the infiltration of immunocyte (such as T lymphocytes, monocyte and neutrophils) into diseased tissues [40-42]. A previous study found that $H$. pylori mainly activated the expression of IL-8 in gastric tissue by the expression of CagA [43]. As shown in the results, the key toxic protein of CagA which is binding to stomach cancer [44] determined to be the crucial factor in those processes. Moreover, dysbacteriosis could happen by the change of IL-8 concentration [28]. TNF- $\alpha$, IL- 6 and IFN- $\gamma$ were determined to be correlated with the severity of tissue inflammation [45-47].

\section{A}

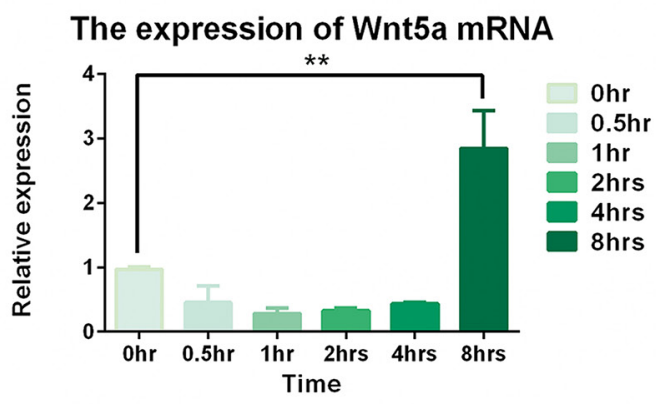

B

The expression of Wnt5a mRNA

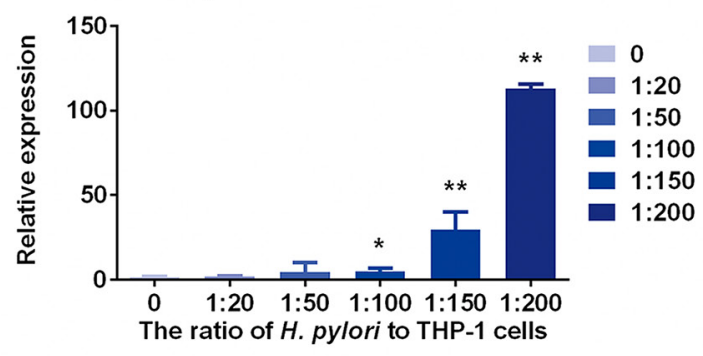

C

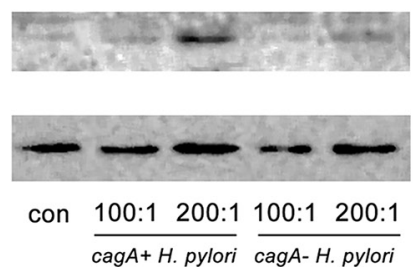

Wnt5a

$\beta$-actin

Figure 3: $\boldsymbol{H}$. pylori up-regulated expression of Wnt5a in mRNA and protein levels. (A) H. pylori was used to infect THP-1 cells at various times at a ratio of 100:1. Real-time PCR was used to detect the expression of Wnt5a mRNA compared to that of GAPDH. (B) $H$. pylori was used to infect the THP-1 cells for 8 hrs at ratios of 10:1, 20:1, 50:1, 100:1, 150:1 and 200:1. (C) THP-1 cells were stimulated by cagA+H. pylori and cagA- H. pylori for $8 \mathrm{hrs}$ at ratios of 0, 100:1 and 200:1. Cells were extracted, and total protein was obtained. Western blot was used to detect protein by antibody against Wnt5a, and $\beta$-actin was used as the protein control. Real-time PCR was used to detect the expression of Wnt5a mRNA. Data were expressed as mean \pm SD from 3 experiments. $* p<0.05$; $* *<0.01$ by one-way ANOVA. 
Our findings confirmed that the secretion of IL- 6 and IFN- $\gamma$ in THP- 1 cells could increase but that of TNF- $\alpha$ was stable after stimulation. The secretion quantities of those three cytokines were relatively lower in comparison to that of IL-8, which suggested that IL-8 was the major cytokine stimulated by $H$. pylori. Those findings might suggest that $H$. pylori could induce the response of the immune system with the invaded pathogens and the progress of inflammation could be exacerbated. It might
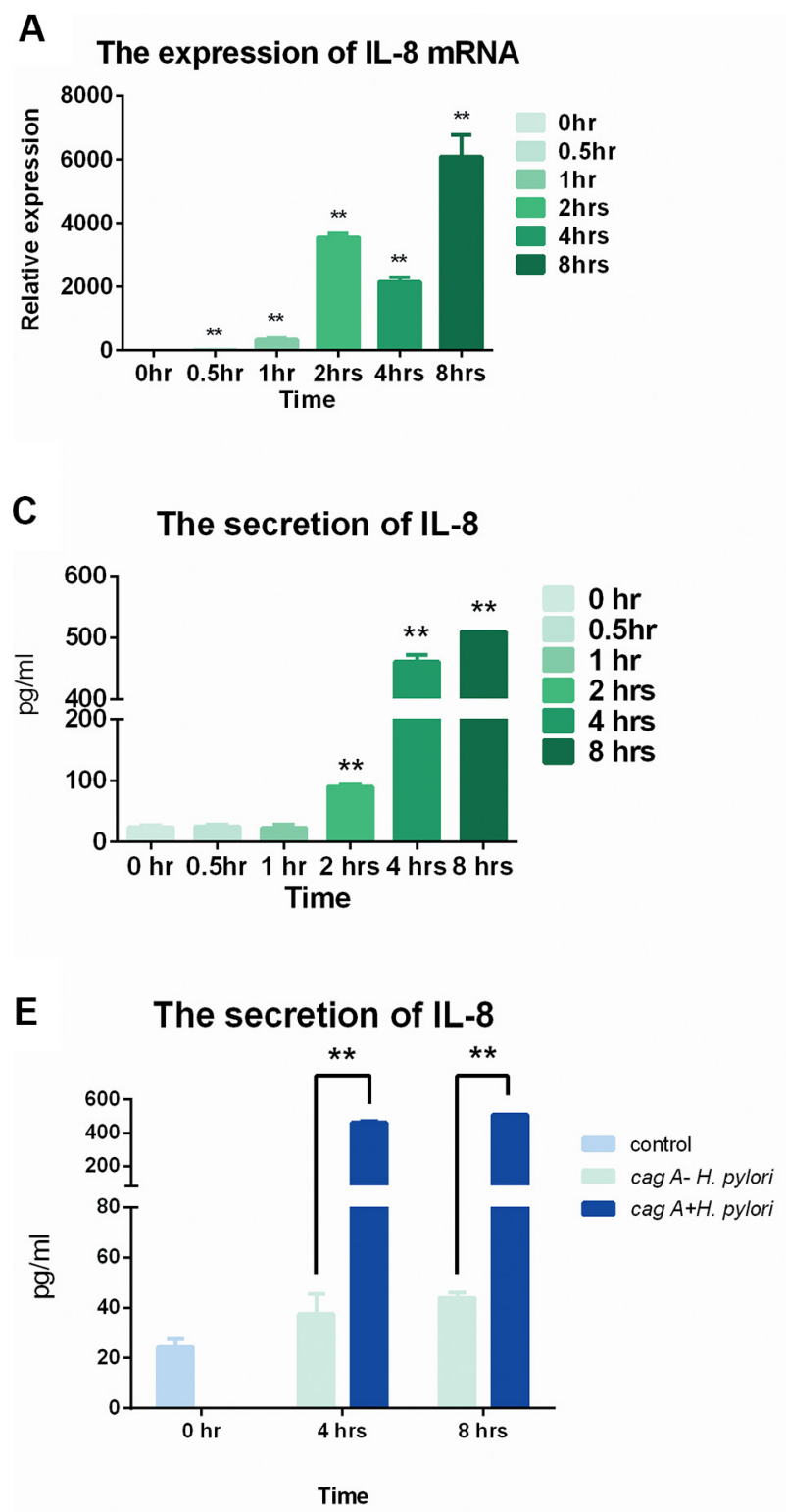

give us a hint that cytokines might serve as mediators on dysbacteriosis.

In a word, this study shows the positive association between $H$. pylori infection and periodontal pathogens. Also, the results indicate that $H$. pylori infection could influence the chronic periodontitis by the change of microecology and inflammation, and induce the severe progress of this disease. Meanwhile, $\operatorname{cag}^{+} H$. pylori shows the similar inflammatory effect on THP-1
B

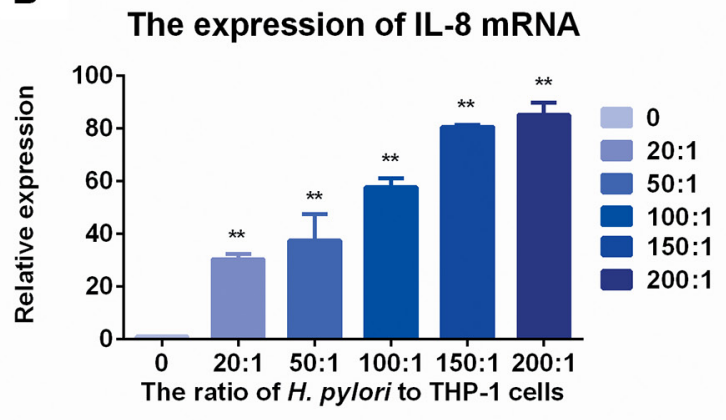

D The secretion of IL-8

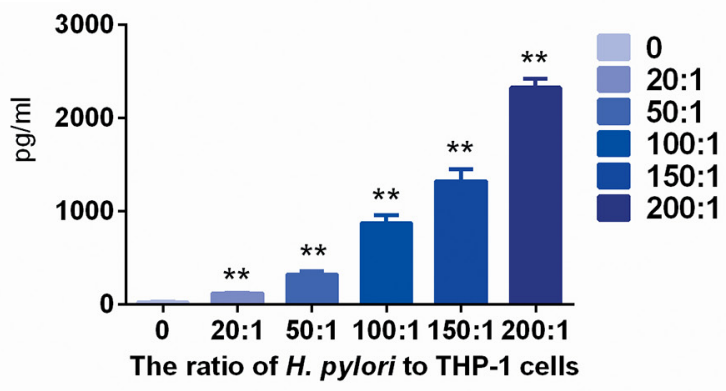

F The secretion of IL-8

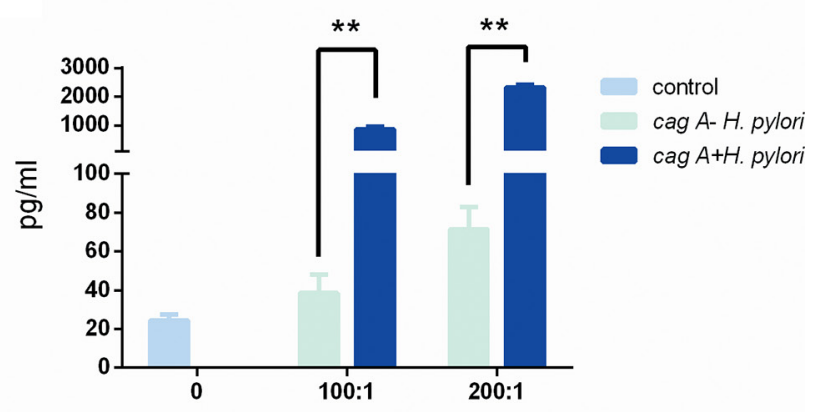

The ratio of $H$. pylori to THP-1 cells

Figure 4: The expression of IL-8 in mRNA and protein levels after stimulation of $\operatorname{cag} A^{+} H$. pylori and cag $A^{-} H$. pylori. (A) H. pylori was used to infect THP-1 cells for various times at a ratio of 100:1. Real-time PCR was used to detect the expression of IL-8 mRNA. (B) H. pylori was used to infect THP-1 cells for $8 \mathrm{hrs}$ at ratios of 0, 10:1, 20:1, 50:1, 100:1, 150:1 and 200:1. Real-time PCR was used to detect the expression of IL-8 mRNA. (C) H. pylori was used to infect the THP-1 cells for various times at a ratio of 100:1. ELISA was used to detect the secretion of IL-8. (D) H. pylori was used to infect THP-1 cells for 8 hrs at ratios of 0, 10:1, 20:1, 50:1, 100:1, 150:1 and 200:1. ELISA was used to detect the secretion of IL-8. Data were expressed as mean \pm SD from 3 experiments. (E) cag $A^{+} H$. $p y l o r i$ and $\operatorname{cag} A^{-} H$. pylori were used to infect the THP-1 cells for $4 \mathrm{hrs}$ and $8 \mathrm{hrs}$ at a ratio of 100:1. (F) cag $A^{+} H$. pylori and cag $A^{-} H$. pylori were used to infect the THP-1 cells for 8 hrs at ratios of 0, 100:1 and 200:1. Data were expressed as mean \pm SD from 3 experiments. ${ }^{*} p<0.05$; $* * p<0.01$ by one-way ANOVA. 
as $P$. gingivalis which suggests that $H$. pylori has the pathogenic effect during the development of periodontitis, CagA might play an irreplaceable role in this process. What we found might give some hints to further therapy of periodontitis, the eradication of

A The secretion of IL-6

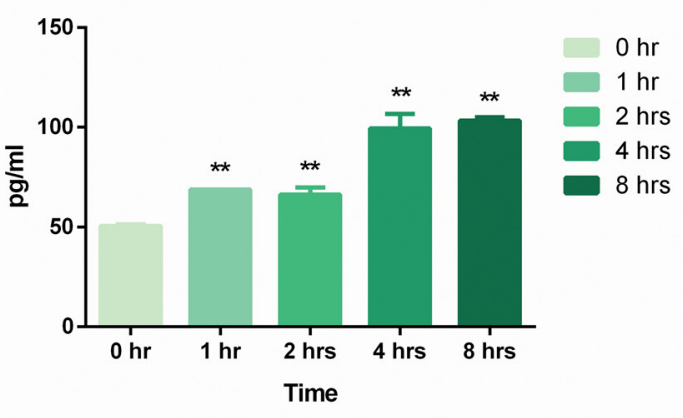

C The secretion of INF-Y

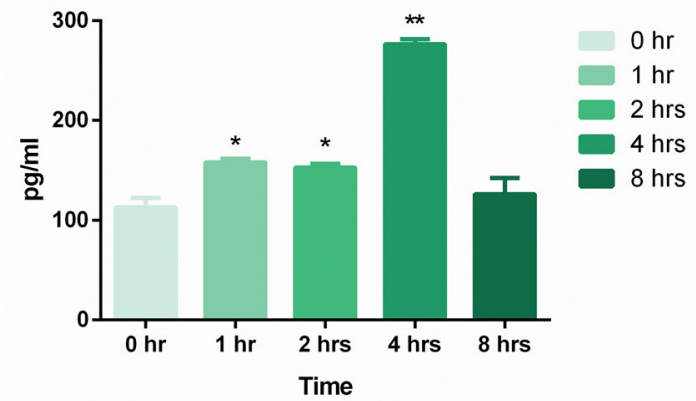

E The secretion of TNF- $\alpha$

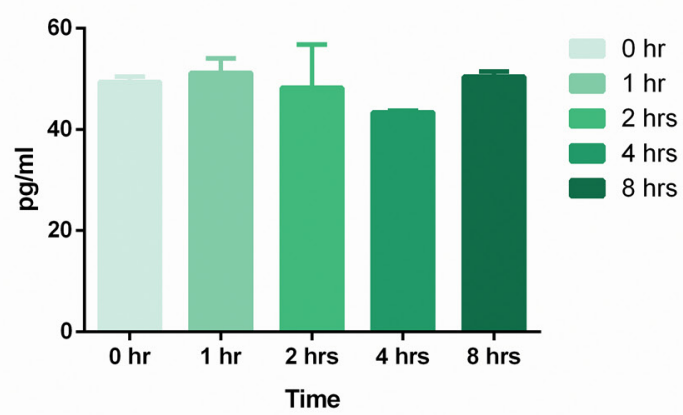

H. pylori could be a key point of chronic periodontal treatment. However, the concrete mechanisms are not clear now, and more patients should be involved and further studies should be done to explore the intrinsic mechanism in future.

B The secretion of IL-6

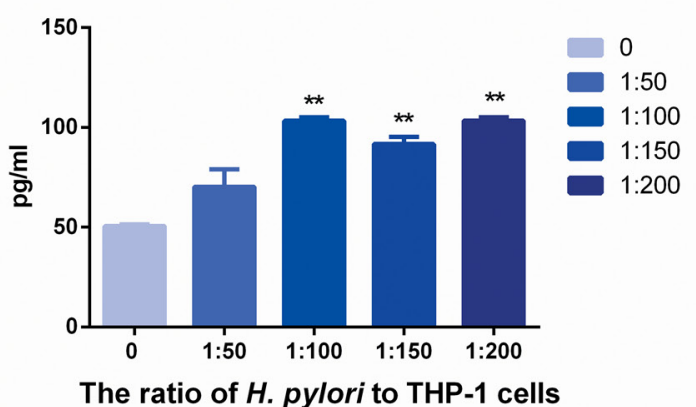

D The secretion of INF-Y

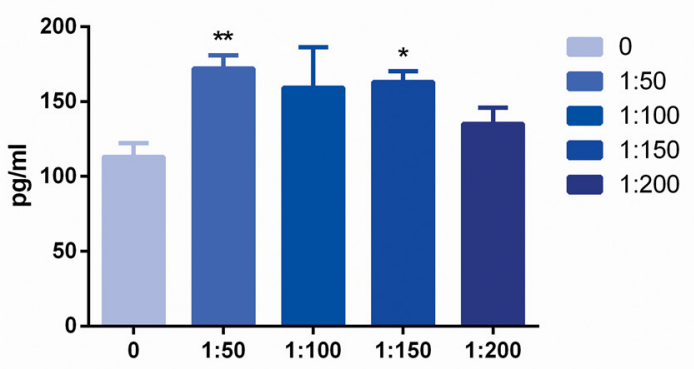

The ratio of $H$. pylori to THP-1 cells

\section{F The secretion of TNF- $\alpha$}

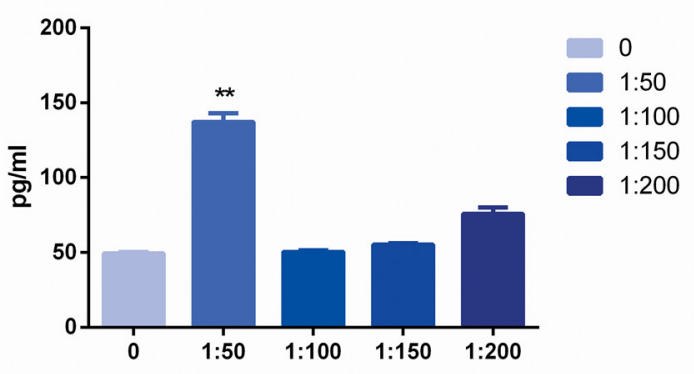

The ratio of $H$. pylori to THP-1 cells

Figure 5: The secretion of IL-6, TNF- $\boldsymbol{\alpha}$ and IFN- $\boldsymbol{\gamma}$ after stimulation of $\boldsymbol{H}$. pylori. (A) (C) (E) H. pylori was used to infect THP-1 cells for various times at a ratio of 100:1. ELISA was used to detect the secretion of IL-6, TNF- $\alpha$ and IFN- $\gamma$. (B) (D) (F) H. pylori was used to infect THP-1 cells for $8 \mathrm{hrs}$ at ratios of 0, 50:1, 100:1, 150:1 and 200:1. ELISA was used to detect the secretion of IL-6, TNF- $\alpha$ and IFN- $\gamma$. Data were expressed as mean \pm SD from 3 experiments. ${ }^{*} p<0.05 ; * p<0.01$ by one-way ANOVA. 


\section{MATERIALS AND METHODS}

\section{Patient sampling}

28 samples from 14 patients with chronic periodontitis from Department of Periodontology, School of Stomatology, Shandong University were collected. The subjects were informed about the procedures and aims of this experiment and signed a consent form. The study was approved by the Medical Ethical Committee of School of Stomatology, Shandong University (Protocol Number: 201302070).

A diagnosis of chronic periodontitis was determined based on the American Academy of Periodontology of Periodontology parameters [48]. Inclusion criteria were age 18 to 60 years, more than $30 \%$ sites with probing depth (PD) deeper than $4 \mathrm{~mm}$; more than 30\% sites with attachment loss (AL) of $2 \mathrm{~mm}$, at least 2 molars remained in oral cavity. The exclusion criteria were antibiotic use in the previous 3 months, professional periodontal therapy in the previous year, diagnosis of systemic diseases that would activate periodontitis, and smoking $>10$ cigarettes a day.

Periodontal index including plaque index (PLI), bleeding index (BI), probing depth (PD) and attachment loss (AL) were evaluated. With a sterilized curettage, subgingival plaque was taken from mesio-buccal site of four first molars with initial probing depth $>5 \mathrm{~mm}$, and then placed in $1 \mathrm{ml}$ phosphate buffered saline (PBS). After centrifuged at $3000 \mathrm{rpm}$ for $5 \mathrm{~min}$, the supernatants were frozen at $-80^{\circ} \mathrm{C}$ for further processing.

\section{Extraction of bacterial DNA from dental plaque and real-time PCR detection of $\boldsymbol{H}$. pylori infection and bacterial composition}

DNA was extracted from samples and purified with the QIAamp DNAMini Kit (QIAGEN GmbH, Hilden, Germany) according to manufacturer's instructions. The purity and yield of DNA were measured by a biophotometer (Eppendorf AG, Hamburg, Germany) with ratio from 1.6 to 1.8 .

Then, Real-time PCR was carried out using $10 \mu \mathrm{l}$ SYBR Premix Ex Taq II (Takara, Kusatsu, Japan), $2 \mu 1$ sample DNA, $7.2 \mu$ d double distilled water, former primer $0.4 \mu \mathrm{l}$ and reverse primer $0.4 \mu \mathrm{l}$. The primers for key bacteria investigated listed in Table 3 . The primers [49] were based on 16s recombinant DNA. The primer of $H$. pylori targeted Urea A gene. We used a real-time PCR system (Bio-Rad Laboratories, USA) with the cycles predenaturation at $94^{\circ} \mathrm{C}$ for $1 \mathrm{~min} ; 45$ amplification cycles including denaturation at $95^{\circ} \mathrm{C}$ for $20 \mathrm{~s}$, annealing at $60^{\circ} \mathrm{C}$ for $20 \mathrm{~s}$, extension $72^{\circ} \mathrm{C}$ for $30 \mathrm{~s}$; then extension at $72^{\circ} \mathrm{C}$ for $1 \mathrm{~min}$. The relative quantification was calculated by $2^{\mathrm{CT}(\text { key pathogen)-CT(universal primer). }}$

\section{Cell culture}

The human leukemia monocytic cell line (THP-1) was acquired from the biochemistry laboratory, Shandong University. The culture medium included RPMI 1640 (Gibco, New York, USA) and fetal bovine serum (Gibco, New York, USA) at $10 \%$ in total and cells were grown at $37^{\circ} \mathrm{C}$ with $5 \% \mathrm{CO}_{2}$ in a suitable incubator.

\section{Culture of $\boldsymbol{H}$. pylori and cell infection}

The H. Pylori strains including cagA-positive standard strains $\left(\mathrm{cag} A^{+} H\right.$. pylori 26695) and isogenic cagA mutants (cag $A^{-} H$. pylori 26695) were obtained from the microbiology laboratory, Shandong University. These strains were cultured under anaerobic conditions at $37^{\circ} \mathrm{C}$ and on specific Brucella agar plates with $7 \%$ horse serum. The cag $A^{+} H$. pylori was used to stimulate cells at a ratio of $100: 1$ for $0,0.5,1,2,4$ and $8 \mathrm{hrs}$. Then, $H$. pylori was used to stimulate cells at a ratio of $0,20: 1,50: 1,100: 1$, 150:1 and 200:1 for $8 \mathrm{hrs}$. The $c a g A^{-} H$. pylori was used to stimulate cells at a ratio of 100:1 and 200:1 for $8 \mathrm{hrs}$. The quantity of cells was calculated by cell counting and the quantity of bacteria was analyzed by spectrophotometry.

\section{Total RNA extraction and PCR}

TRIzol (Takara, Kusatsu, Japan) was used to separate total RNA, and the quality was analyzed by bio-photometry (Eppendorf AG, Hamburg, Germany) with a ratio $(260 / 280 \mathrm{~nm})$ from 1.8-2.0. PrimeScript RT reagent Kit (Takara, Kusatsu, Japan) was used to purify the mRNA and synthesize the cDNA with a thermal cycler. Real-time PCR was conducted using SYBR Premix Ex Taq II (Takara, Kusatsu, Japan) with primers targeting human IL-8, Wnt5a and GAPDH (Table 4). The results were analyzed by $2^{\triangle \Delta C T}$ method.

\section{Western blotting}

Cells were collected from the above experiments and washed twice with PBS. Total Protein Extraction Kit (Bestbio Inc. Shanghai, China) with protease inhibitor and phosphatase inhibitor was used to lyse target cells for total protein extraction. The SDS-PAGE gels ( $10 \%$ acrylamide) were used to resolve the exact amounts of protein, and then transferred and immobilized onto nitrocellulose membranes. The membranes were firstly incubated with Wnt5a polyclonal antibody (Proteintech Group, Inc. Chicago, USA) and then $\beta$-actin antibody (Cell Signaling Technology, Inc. Danvers, USA) at $4^{\circ} \mathrm{C}$ overnight. The membrane was then incubated at room temperature for an additional 60 min with secondary antibody. Finally, Immobilon ${ }^{\mathrm{TM}}$ Western Chemiluminescent HRP Substrate (Millipore Corporation, Billerica, USA) was used to detect the immune-active signal of target protein. 
Table 3: Primers for real-time PCR to detect target pathogens

\begin{tabular}{|c|c|c|c|}
\hline Primers & Product size (bp) & $\begin{array}{c}\text { Target } \\
\text { gene }\end{array}$ & Annealing temperature $\left({ }^{\circ} \mathrm{C}\right)$ \\
\hline \multicolumn{4}{|l|}{ Universal primer } \\
\hline 5'-ACTCCTACGGGAGGCAGCAGT-3' & 180 & 16s rRNA & 60 \\
\hline \multicolumn{4}{|l|}{ 5'-TATTACCGCGGCTGCTGGC-3' } \\
\hline \multicolumn{4}{|l|}{ H. pylori } \\
\hline 5' -CAAGAAGGGCGCACTCTTTT-3' & 250 & Ure A & 60 \\
\hline \multicolumn{4}{|l|}{ 5' -CGATTTGAACCGGTCTGTCG-3' } \\
\hline \multicolumn{4}{|l|}{ F. nuclearum } \\
\hline 5' -TACCAACAGAAGAAGTGACGGCTAA-3' & 162 & 16s rRNA & 60 \\
\hline \multicolumn{4}{|l|}{ 5' -ATACAGTTTCCAACGCAATACAGAG-3' } \\
\hline \multicolumn{4}{|l|}{ S. mutans } \\
\hline 5'-GGTCAGGAAAGTCTGGAGTAAAAGGCTA-3' & 260 & 16s rRNA & 60 \\
\hline \multicolumn{4}{|l|}{ 5' -GCGTTAGCTCCGGCACTAAGCC-3' } \\
\hline \multicolumn{4}{|l|}{ S. sanguis } \\
\hline 5' -TTCAAAGCCAAGACCAAGCTAGT-3' & 88 & 16s rRNA & 60 \\
\hline \multicolumn{4}{|l|}{ 5' -CCAGCCTGAGATTCAGCTTGT-3' } \\
\hline \multicolumn{4}{|l|}{ A. actinomycetemcomitans } \\
\hline 5' -CTTACCTACTCTTGACATCCGAA-3' & 77 & 16s rRNA & 60 \\
\hline \multicolumn{4}{|l|}{ 5' -ATGCAGCACCTGTCTCAAAGG-3' } \\
\hline \multicolumn{4}{|l|}{ P. gingivalis } \\
\hline 5' -TGTAGATGACTGATGGTGAAAACC-3' & 178 & 16s rRNA & 60 \\
\hline \multicolumn{4}{|l|}{ 5' -ACGTCATCCACACCTTCCTC-3' } \\
\hline \multicolumn{4}{|l|}{ T. forsythia } \\
\hline 5' -AGCGATGGTAGCAATACCTGTC-3' & 88 & 16s rRNA & 60 \\
\hline \multicolumn{4}{|l|}{ 5' -TTCGCCGGGTTATCCTC-3' } \\
\hline \multicolumn{4}{|l|}{ P. intermedia } \\
\hline 5' -TCCACCGATGAATCTTTGGTC-3' & 98 & 16s rRNA & 60 \\
\hline \multicolumn{4}{|l|}{ 5' -АТCСААССТТСССТССАСТC-3' } \\
\hline \multicolumn{4}{|l|}{ T. denticola } \\
\hline 5' -AGAGCAAGCTCTCCCTTACCGT-3' & 105 & 16s rRNA & 60 \\
\hline 5' -TAAGGGCGGCTTGAAATAATGA-3' & & & \\
\hline
\end{tabular}

Table 4: Primers for real-time PCR to detect the expression of target genes

\begin{tabular}{lccc}
\multicolumn{1}{c}{ Primers } & Product size (bp) & Target gene & Annealing temperature $\left({ }^{\circ} \mathbf{C}\right)$ \\
\hline Wnt5a & & & \\
5' -TCCTCCGTGTTGTGATGTGA-3' & 225 & Wnt5a mRNA & 60 \\
5' -GATACGCTGCAACACCTCTG-3' & & & \\
GAPDH & & GAPDH & 60 \\
5' -ACCACAGTCCATGCCATCAC-3' & 226 & mRNA & \\
5' -ACCACCCTGTTGCTGTA-3' & & & \\
IL-8 & & & 60 \\
5' -TCAGAGACAGCAGAGCACAC-3' & 159 & IL-8 mRNA & \\
5' -GGCAAAACTGCACCTTCACA-3' & & & \\
\hline
\end{tabular}




\section{Detection of human IL-8, IL-6, TNF- $\alpha$ and IFN- $\gamma$}

THP-1 cells were used in this part to detect the secretion of IL- 8, IL- 6 , TNF- $\alpha$ and IFN- $\gamma$. The procedure of stimulation was the same as culture of $H$. pylori and cell infection above. Cell supernatant, however, was collected to detect the protein. The secretion of IL-8, IL-6, TNF- $\alpha$ and IFN- $\gamma$ were detected by ELISA kits (Ebioscience, San Diego, USA). The preparation and protocol were followed according to the instructions. In each group, the absorbance of IL-8, IL$6, \mathrm{TNF}-\alpha$ and IFN- $\gamma$ was detected by spectrophotometry at $450 \mathrm{~nm}$, and each experiment was repeated three times. The resulting values were expressed in $\mathrm{pg} / \mathrm{ml}$.

\section{Statistical analysis}

Data were shown as means with standard error (SD) and then analyzed by use of SPSS Client 21.0. Variance between two groups was compared by two-way $t$-test and variance among more than two groups was evaluated by one-way ANOVA. Statistical probability of $p<0.05$ was considered significant.

\section{ACKNOWLEDGMENTS}

The authors acknowledge Mr. Yiqun Su, Shandong University, for assistance with obtaining the clinical samples.

\section{CONFLICTS OF INTEREST}

All authors have no conflicts of interest.

\section{GRANT SUPPORT}

This study was funded by the National Natural Science Foundation of China (No. 81371157, 81100756, 81471991, 81571960, 81372680), Science and Technology Program of Shandong Province (No. 2014GSF118075) and the Construction Engineering Special Fund of Taishan Scholars (No. ts201511106). The funders had no role in study design, data collection and analysis, decision to publish, or preparation of the manuscript.

\section{REFERENCES}

1. Pihlstrom BL, Michalowicz BS, Johnson NW. Periodontal diseases. Lancet. 2005; 366:1809-1820.

2. Consensus report. Periodontal diseases: pathogenesis and microbial factors. Ann Periodontol. 1996; 1:926-932.

3. Nabi N, Chaouachi M, Zellama MS, Ben Hafsa A, Mrabet B, Said K, Fathia HS. A new QRT-PCR assay designed for the differentiation between elements provided from Agrobacterium sp. in GMOs plant events and natural Agrobacterium sp. bacteria. Food Chem. 2016; 196:58-65.
4. Dewhirst FE, Chen T, Izard J, Paster BJ, Tanner AC, Yu WH, Lakshmanan A, Wade WG. The human oral microbiome. J BACTERIOL. 2010; 192:5002-5017.

5. Slots J. Bacterial specificity in adult periodontitis. A summary of recent work. J Clin Periodontol. 1986; 13:912-917.

6. Ricardo AC, Athavale A, Chen J, Hampole H, Garside D, Marucha P, Lash JP. Periodontal disease, chronic kidney disease and mortality: results from the third national health and nutrition examination survey. BMC NEPHROL. 2015; 16.

7. Maharaj B, Vayej AC. Oral health of patients with severe rheumatic heart disease. Cardiovasc J Afr. 2012; 23:336-339.

8. Salazar CR, Francois F, Li Y, Corby P, Hays R, Leung C, Bedi S, Segers S, Queiroz E, Sun J, Wang B, Ho H, Craig R, et al. Association between oral health and gastric precancerous lesions. Carcinogenesis. 2012; 33:399-403.

9. Salama NR, Hartung ML, Müller A. Life in the human stomach: persistence strategies of the bacterial pathogen Helicobacter pylori. Nat Rev Microbiol. 2013; 11:385-399.

10. Gisbert JP, Moreno-Otero R, Pajares JM. Prevalence of Helicobacter pylori infection in chronic liver disease and relationship with its complications: systematic review and meta-analysis. Med Clin (Barc). 2002; 119:464-474.

11. Desai HG, Gill HH, Shankaran K, Mehta PR, Prabhu SR. Dental plaque: a permanent reservoir of Helicobacter pylori? Scand J Gastroenterol. 1991; 26:1205-1208.

12. Anand PS, Kamath KP, Anil S. Role of dental plaque, saliva and periodontal disease in Helicobacter pylori infection. World J Gastroenterol. 2014; 20:5639-5653.

13. Dye BA, Kruszon-Moran D, McQuillan G. The relationship between periodontal disease attributes and Helicobacter pylori infection among adults in the United States. Am J Public Health. 2002; 92:1809-1815.

14. Silva DG, Stevens RH, Macedo JM, Albano RM, Falabella ME, Fischer RG, Veerman EC, Tinoco EM. Presence of Helicobacter pylori in supragingival dental plaque of individuals with periodontal disease and upper gastric diseases. ARCH Oral Biol. 2010; 55:896-901.

15. Salehi MR, Shah AM, Naghsh N, Hajisadeghi S, Ajami EA Comparison in Prevalence of Helicobacter pylori in the Gingival Crevicular Fluid from Subjects with Periodontitis and Healthy Individuals using Polymerase Chain Reaction. J Dent Res Dent Clin Dent Prospects. 2013; 7:238-243.

16. Nanbara H, Wara-aswapati N, Nagasawa T, Yoshida Y, Yashiro R, Bando Y, Kobayashi H, Khongcharoensuk J, Hormdee D, Pitiphat W, Boch JA, Izumi Y. Modulation of Wnt5a expression by periodontopathic bacteria. Plos One. 2012; 7:e34434.

17. Roel N. Wnt signaling in disease and in development. Cell Res. 2005; :28-32.

18. Christman MN, Goetz DJ, Dickerson E, McCall KD, Lewis CJ, Benencia F, Silver MJ, Kohn LD, Malgor R. Wnt5a is expressed in murine and human atherosclerotic lesions. Am J Physiol Heart Circ Physiol. 2008; 294:H2864-H2870. 
19. Huang CL, Liu D, Nakano J, Ishikawa S, Kontani K, Yokomise H, Ueno M. Wnt5a expression is associated with the tumor proliferation and the stromal vascular endothelial growth factor--an expression in non-small-cell lung cancer. J Clin Oncol. 2005; 23:8765-8773.

20. Koch AE, Polverini PJ, Kunkel SL, Harlow LA, DiPietro LA, Elner VM, Elner SG, Strieter RM. Interleukin-8 as a macrophage-derived mediator of angiogenesis. Science. 1992; 258:1798-1801.

21. Tsunoda K, Tsujino I, Koshi R, Sugano N, Sato S, Asano M. Nicotine-Mediated Ca -Influx Induces IL-8 Secretion in Oral Squamous Cell Carcinoma Cell. J Cell Biochem. 2015.

22. Yee M, Kim S, Sethi P, Duzgunes N, Konopka K. Porphyromonas gingivalis stimulates IL-6 and IL-8 secretion in GMSM-K, HSC-3 and H413 oral epithelial cells. Anaerobe. 2014; 28:62-67.

23. Cvikl B, Lussi A, Moritz A, Sculean A, Gruber R. Sterilefiltered saliva is a strong inducer of IL-6 and IL-8 in oral fibroblasts. Clin Oral Investig. 2015; 19:385-399.

24. Chen XT, Tan JY, Lei LH, Chen LL. Cytokine levels in plasma and gingival crevicular fluid in chronic periodontitis. Am J Dent. 2015; 28:9-12.

25. Mattuella LG, Campagnaro MB, Vargas AE, Xavier LL, Oppermann RV, Chies JA, Miranda LA. Plasma cytokines levels in aggressive and chronic periodontitis. Acta Odontol Scand. 2013; 71:683-688.

26. Ebersole JL, Kirakodu S, Novak MJ, Stromberg AJ, Shen S, Orraca L, Gonzalez-Martinez J, Burgos A, Gonzalez OA. Cytokine gene expression profiles during initiation, progression and resolution of periodontitis. J Clin Periodontol. 2014; 41:853-861.

27. Bliss CJ, Golenbock DT, Keates S, Linevsky JK, Kelly CP. Helicobacter pylori lipopolysaccharide binds to CD14 and stimulates release of interleukin-8, epithelial neutrophil-activating peptide 78 , and monocyte chemotactic protein 1 by human monocytes. Infect Immun. 1998; 66:5357-5363.

28. Reti KL, Tymensen LD, Davis SP, Amrein MW, Buret AG. Campylobacter jejuni increases flagellar expression and adhesion of noninvasive Escherichia coli: effects on enterocytic Toll-like receptor 4 and CXCL-8 expression. Infect Immun. 2015; 83:4571-4581.

29. Zheng P, Zhou W. Relation between periodontitis and helicobacter pylori infection. Int J Clin Exp Med. 2015; 8:16741-16744.

30. Gebara EC, Pannuti C, Faria CM, Chehter L, Mayer MP, Lima LA. Prevalence of Helicobacter pylori detected by polymerase chain reaction in the oral cavity of periodontitis patients. Oral Microbiol Immunol. 2004; 19:277-280.

31. Bickel M, Axtelius B, Solioz C, Attstrom R. Cytokine gene expression in chronic periodontitis. J Clin Periodontol. 2001; 28:840-847.

32. Ouhara K, Kawai T, Silva MJ, Fujita T, Hayashida K, Karimbux NY, Kajiya M, Shiba H, Kawaguchi H,
Kurihara H. Expression levels of novel cytokine IL-32 in periodontitis and its role in the suppression of IL-8 production by human gingival fibroblasts stimulated with Porphyromonas gingivalis. J Oral Microbiol. 2012; 4.

33. Kubar A, Saygun I, Ozdemir A, Yapar M, Slots J. Realtime polymerase chain reaction quantification of human cytomegalovirus and Epstein-Barr virus in periodontal pockets and the adjacent gingiva of periodontitis lesions. J Periodontal Res. 2005; 40:97-104.

34. Robinson PG. The significance and management of periodontal lesions in HIV infection. Oral Dis. 2002; 8:91-97.

35. Wichelhaus A, Brauchli L, Song Q, Adler G, Bode G. Prevalence of Helicobacter pylori in the adolescent oral cavity: dependence on orthodontic therapy, oral flora and hygiene. J Orofac Orthop. 2011; 72:187-195.

36. Zambon JJ. Actinobacillus actinomycetemcomitans in human periodontal disease. J Clin Periodontol. 1985; 12:1-20.

37. Slots J, Ting M. Actinobacillus actinomycetemcomitans and Porphyromonas gingivalis in human periodontal disease: occurrence and treatment. Periodontol 2000. 1999; 20:82-121.

38. Sen M, Lauterbach K, El-Gabalawy H, Firestein GS, Corr M, Carson DA. Expression and function of wingless and frizzled homologs in rheumatoid arthritis. Proc Natl Acad Sci USA. 2000; 97:2791-2796.

39. Caliskan R, Sayi YA, Tokman HB, Sofyali E, Erzin YZ, Akgul O, Kurt A, Kalayci F, Ziver T, Yuksel P, Bal K, Kocazeybek B. The cytokine response in THP-1 (monocyte) and HL-60 (neutrophil-differentiated) cells infected with different genotypes of Helicobacter pylori strains. Turk J Gastroenterol. 2015; 26:297-303.

40. Bartchewsky WJ, Martini MR, Masiero M, Squassoni AC, Alvarez MC, Ladeira MS, Salvatore D, Trevisan M, Pedrazzoli JJ, Ribeiro ML. Effect of Helicobacter pylori infection on IL-8, IL-1beta and COX-2 expression in patients with chronic gastritis and gastric cancer. Scand J Gastroenterol. 2009; 44:153-161.

41. Sharma SA, Tummuru MK, Miller GG, Blaser MJ. Interleukin-8 response of gastric epithelial cell lines to Helicobacter pylori stimulation in vitro. Infect Immun. 1995; 63:1681-1687.

42. Eskandari-Nasab E, Sepanjnia A, Moghadampour M, Hadadi-Fishani M, Rezaeifar A, Asadi-Saghandi A, Sadeghi-Kalani B, Manshadi MD, Pourrajab F, Pourmasoumi H. Circulating levels of interleukin (IL)-12 and IL-13 in Helicobacter pylori-infected patients, and their associations with bacterial CagA and VacA virulence factors. Scand J Infect Dis. 2013; 45:342-349.

43. Ferreira RM, Pinto-Ribeiro I, Wen X, Marcos-Pinto R, Dinis-Ribeiro M, Carneiro F, Figueiredo C. Helicobacter pylori cagA Promoter Region Sequences Influence CagA Expression and Interleukin 8 Secretion. J Infect Dis. 2016; 213:669-673.

44. Salama NR, Hartung ML, Muller A. Life in the human stomach: persistence strategies of the bacterial pathogen Helicobacter pylori. Nat Rev Microbiol. 2013; 11:385-399. 
45. Tanaka T, Narazaki M, Kishimoto T. IL-6 in inflammation, immunity, and disease. Cold Spring Harb Perspect Biol. 2014; 6:a16295.

46. Oe Y, Mochizuki K, Miyauchi R, Misaki Y, Kasezawa N, Tohyama K, Goda T. Plasma TNF-alpha Is Associated with Inflammation and Nutrition Status in Community-Dwelling Japanese Elderly. J Nutr Sci Vitaminol (Tokyo). 2015; 61:263-269.

47. Fuchs A. ILC1s in Tissue Inflammation and Infection. Front Immunol. 2016; 7:104.
48. 1999 International International Workshop for a Classification of Periodontal Diseases and Conditions. Papers. Oak Brook, Illinois, October 30-November 2, 1999. Ann Periodontol. 1999; 4:1-112.

49. Maeda H, Fujimoto C, Haruki Y, Maeda T, Kokeguchi S, Petelin M, Arai H, Tanimoto I, Nishimura F, Takashiba S. Quantitative real-time PCR using TaqMan and SYBR Green for Actinobacillus actinomycetemcomitans, Porphyromonas gingivalis, Prevotella intermedia, tetQ gene and total bacteria. Fems Immunol Med Microbiol. 2003; 39:81-86. 